\title{
Computed tomography assessment of lung volume changes after bronchial valve treatment
}

\author{
H.O. Coxson*,\#, P.V. Nasute Fauerbach*, C. Storness-Bliss*,\#, N.L. Müller*, \\ S. Cogswell*,\#, D.H. Dillard ", C.L. Finger" and S.C. Springmeyer"
}

ABSTRACT: The aim of the present study was to correlate clinical outcome measures following treatment with bronchial valves with regional lung volume. Computed tomography (CT) scan data from 57 subjects with severe emphysema were obtained from nine North American clinical trial sites. IBV ${ }_{\mathbb{R}}$ Valves (Spiration, Inc., Redmond, WA, USA) were placed to occlude segmental and subsegmental bronchi in right and left upper lobes using a flexible bronchoscope. Subjects completed a St George's Respiratory Questionnaire (SGRQ), pulmonary function test (PFT) and exercise capacity test. CT scans were analysed at baseline and at 1, 3 or 6 months after treatment to measure total and lobar lung density, volume and mass.

Total lung volumes measured using CT were strongly correlated with PFT and did not change with treatment. However, the treated upper lobes significantly decreased in volume in $88 \%$ of the observations, by mean \pm SD $335 \pm 444 \mathrm{~mL}$, or a decrease of $10.2 \%$ in the 6 month data. The untreated lobes had an $11.6 \%$ increase in volume. Changes in regional lung volume were associated with clinically meaningful improvements in SGRQ (-8.95 \pm 16.22$)$, but not clinically meaningful PFT changes.

The significant health status improvements reported by subjects following bilateral bronchial valve treatment are associated with regional lung volume changes and interlobar shift measured using computed tomography.

KEYWORDS: Computed tomography, emphysema, intrabronchial valve, lung volume reduction surgery

hronic obstructive pulmonary disease (COPD) is the most common form of primary pulmonary disability [1, 2] and an important cause of mortality when severe. As COPD becomes an end-stage disease, palliative surgical procedures, such as bullectomy for giant bullae, lung volume reduction surgery (LVRS) and lung transplantation, are the only potential treatments remaining.

The National Emphysema Treatment Trial (NETT) and some other smaller studies have shown that, in a selected population of patients with heterogeneous distribution of emphysema and upper-lobe predominance, LVRS can improve patient quality of life, as well as respiratory function, exercise capacity and survival [3-8]. However, surgery in these already high-risk patients has a significant morbidity (20$30 \%$ ) and a considerable operative mortality $(7.9 \%)$ within 90 days of the procedure [9].
Therefore, minimally invasive techniques have been proposed as a method to reduce lung volume in these patients without undergoing open thoracotomy [10-15]. One of these new treatments is a one-way valve, which is placed in the segmental bronchi of the most diseased lobes, generally the upper lobes, to prevent air from entering these portions of the lung during normal inspiration while still allowing air to exit. The original hypothesis for this procedure was that the delivery of gas to the treated lobes would be lower than the absorption of gas in these regions resulting in lobar atelectasis, and a reduction of total volume in the diseased lung $[11,12,15]$. This overall reduction in lung volume would result in functional and clinical improvements, similar to those seen with LVRS, but without the invasive surgical procedure. However, several studies have found that the majority of subjects with clinical improvement did not have atelectasis and total lung volume
AFFILIATIONS

*Dept of Radiology, Vancouver General Hospital,

* James Hogg iCAPTURE Centre for Cardiovascular and Pulmonary Research, Vancouver, BC, Canada, and

"Spiration Inc., Redmond, WA, USA

CORRESPONDENCE

H.O. Coxson

Department of Radiology

Vancouver General Hospital 855 West 12th Ave

Room 3350 JPN

Vancouver

$\mathrm{BC}$

V5Z $1 \mathrm{M} 9$

Canada

Fax: 16048754319

E-mail: harvey.coxson@vch.ca

Received:

April 132008

Accepted after revision:

July 192008

SUPPORT STATEMENT

H.O. Coxson is a British Columbia

Lung Association/Canadian Institutes of Health Research New Investigator Award. This study uses data obtained from a pilot study that has been registered at clinicaltrials.gov (NCT00145548).

\section{STATEMENT OF INTEREST}

Statements of interest for H.O. Coxson, N.L. Müller, D.H. Dillard, C.L. Finger and S.C. Springmeyer, and for the study itself, can be found at www.erj.ersjournals.com/misc/ statements.shtml 
reduction, so other mechanisms of action have been considered and investigated $[15,16]$.

The purpose of the present study was to correlate clinical outcome measures with objective and subjective quantification of lobar lung volumes in patients with severe upper-lobe predominant emphysema treated with one-way bronchial valves. The current hypothesis was that as bronchial valves block distal airflow, the treated lobes would have a decrease in volume that could not be measured using physiological lung pulmonary function methods.

\section{MATERIALS AND METHODS}

Computed tomography (CT) scan data from 57 subjects with severe emphysema were obtained from nine North American clinical trial sites. All studies were approved by the appropriate institutional review board or ethics committee and all subjects gave informed consent to receive treatment with the $\mathrm{IBV}_{\circledast}$ Valve System (Spiration, Inc., Redmond, WA, USA) and have their clinical information collected.

These 57 subjects are a subset of 98 subjects from North American pilot studies (clinicaltrials.gov identifier NCT00145548) in which CT scan data could be obtained. All 98 subjects received an initial CT scan to determine whether they met the selection criteria for severe, upper-lobe predominant emphysema. The first 34 subjects enrolled in the trial received a second CT scan after 1 month to plan for a second bronchoscopic procedure, which produced 34 paired baseline and 1-month scans for analysis. When the quantitative CT study was initiated, subjects that had not yet reached their 6month follow-up received another CT scan; this provided 16 paired scans for baseline and 6-month analyses. Finally, subjects enrolled after the initiation of the quantitative CT scan also received a CT scan at 3 months post-valve placement to provide a total of 34 paired baseline and 3-month scans. Some subjects received CT scans at more than one time point, and accordingly, the number of paired data sets exceeds the number of patients.

The inclusion/exclusion criteria of subjects have been previously reported [15]. Briefly, subjects were included if they had severe airflow limitation (forced expiratory volume in one second (FEV1) $\leqslant 45 \%$ predicted), hyperinflation (total lung capacity (TLC) $\geqslant 100 \%$ pred and residual volume (RV) $\geqslant 150 \%$ pred), a 6-min walk test (6MWT) distance of $>140 \mathrm{~m}$ and severe emphysema that was determined to be upper-lobe predominant using the radiological comparison method that gave predictive results in the NETT [17]. Subjects were excluded if they had the high-risk criteria defined by NETT, signs of active infection or bronchospasm, were deemed to have lower-lobe predominant, diffuse, or superior segment of the lower lobe predominant using the radiological comparison method, or were listed for LVRS or lung transplantation.

\section{Bronchial valve placement}

The bronchoscopic procedure and valve placement has been previously described [15]. Briefly, after anaesthesia and endotracheal intubation, the sizes of the target airways were determined using a calibrated balloon catheter. Valves of the appropriate size were placed in both upper lobes using previously described techniques [15].

\section{Clinical data}

All subjects received a pulmonary function test (PFT) including spirometry (FEV1 and forced vital capacity (FVC)), plethysmography for static lung volumes (TLC, RV and functional residual capacity) as well as the diffusing capacity of the lung for carbon monoxide $(D \mathrm{~L}, \mathrm{CO})$ using the single-breath carbon monoxide method. These measures were made at baseline $(n=57), 1$ month $(n=52), 3$ months $(n=53)$ and 6 months $(n=45)$ after treatment with bronchial valves. Disease-specific health-related quality of life (HRQL) was measured using the St George's Respiratory Questionnaire (SGRQ) at the described time points. The SGRQ was completed during clinical stability with a four-point or greater change indicating a clinically meaningful improvement and defined as a responder.

\section{Radiological imaging}

CT scans were obtained using a high-resolution CT protocol (1 or $1.25 \mathrm{~mm}$ slice thickness, $10 \mathrm{~mm}$ gap; $\mathrm{n}=4$ ), a multislice CT protocol (1 mm slice thickness, contiguous images; $n=13$ ) or thick slice protocol ( $5 \mathrm{~mm}$ slice thickness, contiguous images; $\mathrm{n}=40$ ).

\section{Data analysis}

All CT scans were analysed at the University of British Columbia (Vancouver, BC, Canada) using both a qualitative and a quantitative procedure. For the qualitative analysis, two independent readers (P.V. Nasute Fauerbach and N.L. Müller) reviewed the $\mathrm{CT}$ scans. For the baseline $\mathrm{CT}$ scans the following parameters were considered: distribution of emphysema (upper-lobe or nonupper-lobe predominant); predominant type of emphysema (centrilobular, panacinar or paraseptal); and the extent of emphysema (marked/grade 3: 50-75\%; and severe/grade $4:>75 \%)$. This allowed comparison with the local site assessments for the inclusion criteria of severe, upperlobe predominant emphysema. In the follow-up CT scans the following were reported: presence of volume loss distal to the endobronchial valve and its grade if present (no volume loss, linear atelectasis, mild atelectasis: volume loss equivalent to less than one segment; moderate atelectasis: volume loss was equivalent to one or more segments; or complete atelectasis: when the whole lobe was affected).

The quantitative analysis was performed by two different readers (C. Storness-Bliss and S. Cogswell) using custom software (EmphylxJ, Vancouver, BC, Canada) as previously reported $[18,19]$. Briefly, the lung parenchyma was segmented from the chest wall and large central blood vessels in all CT images using a modified border-tracing algorithm with a prior position-knowledge algorithm. Total lung volume was calculated by summation of the segmented pixel area in each slice and multiplying by the slice thickness. Lobar volume was calculated by manually tracing the fissures and summation of the pixels as above. Three cases were analysed by both observers to check for interobserver variation in the fissure-tracing technique. The mean CT attenuation measured in $\mathrm{HU}$ of the lobe and total lung were calculated and converted to a measure of density in $\mathrm{g} \cdot \mathrm{mL}^{-1}$ by adding 1,000 to the $\mathrm{HU}$ number and dividing by $1,000[20,21]$. The mean density of the lung was then multiplied by the lung volume to estimate lung mass.

\section{Statistical analysis}

The difference between contiguous variables was tested using a paired t-test. Correlation estimates were calculated using 


\begin{tabular}{|c|c|c|c|c|}
\hline \multirow[t]{2}{*}{ TABLE 1} & \multicolumn{4}{|c|}{$\begin{array}{l}\text { Clinical outcome measures over time: before } \\
\text { and after treatment and the difference between } \\
\text { baseline and time after treatment }\end{array}$} \\
\hline & Baseline & 1 month & 3 months & 6 months \\
\hline FEV $_{1} \mathrm{~L}$ & $0.84 \pm 0.23$ & $0.82 \pm 0.22$ & $0.80 \pm 0.22$ & $0.79 \pm 0.23$ \\
\hline Difference $\mathrm{L}$ & & $-0.03 \pm 0.14$ & $-0.03 \pm 0.17$ & $-0.04 \pm 0.16^{*}$ \\
\hline Subjects n & 57 & 55 & 54 & 45 \\
\hline FVC L & $2.76 \pm 0.84$ & $2.75 \pm 0.83$ & $2.61 \pm 0.74$ & $2.59 \pm 0.73$ \\
\hline Difference $L$ & & $-0.03 \pm 0.48$ & $-0.12 \pm 0.46$ & $-0.11 \pm 0.60^{*}$ \\
\hline Subjects $\mathrm{n}$ & 57 & 55 & 54 & 45 \\
\hline TLC L & $7.78 \pm 1.40$ & $7.65 \pm 1.41$ & $7.74 \pm 1.49$ & $7.64 \pm 1.51$ \\
\hline Difference $L$ & & $-0.11 \pm 0.68$ & $-0.03 \pm 0.73$ & $-0.12 \pm 0.63$ \\
\hline Subjects n & 56 & 55 & 54 & 45 \\
\hline RV L & $4.90 \pm 1.04$ & $4.90 \pm 1.05$ & $5.10 \pm 1.15$ & $4.98 \pm 1.26$ \\
\hline Difference $L$ & & $0.03 \pm 0.87$ & $0.19 \pm 0.93$ & $0.02 \pm 0.94$ \\
\hline Subjects $n$ & 56 & 55 & 54 & 45 \\
\hline$D \mathrm{~L}, \mathrm{CO} \mathrm{mL} \cdot \mathrm{min}^{-1}$ & $9.50 \pm 3.13$ & $9.67 \pm 3.26$ & $8.97 \pm 3.06$ & $9.10 \pm 2.76$ \\
\hline $\begin{array}{l}\text { Difference } \\
\mathrm{mL} \cdot \mathrm{min}^{-1}\end{array}$ & & $0.09 \pm 2.11$ & $-0.49 \pm 2.17$ & $-0.29 \pm 1.99$ \\
\hline Subjects $n$ & 56 & 54 & 54 & 45 \\
\hline 6MWT m & $336 \pm 85$ & $345 \pm 90$ & $349 \pm 85$ & $348 \pm 97$ \\
\hline Difference m & & $4 \pm 56$ & $9 \pm 57$ & $12 \pm 65$ \\
\hline Subjects $\mathrm{n}$ & 57 & 54 & 54 & 45 \\
\hline SGRQ & $58.2 \pm 12.6$ & $52.7 \pm 13.6$ & $54.5 \pm 18.0$ & $50.0 \pm 19.1$ \\
\hline Difference & & $-5.49 \pm 13.60^{\star *}$ & $-4.28 \pm 15.81^{*}$ & $-8.95 \pm 16.22^{\#}$ \\
\hline $\mathrm{n}$ & 56 & 55 & 54 & 45 \\
\hline $\begin{array}{l}\text { Data are prese } \\
\text { expiratory volum } \\
\text { capacity; RV: res } \\
\text { monoxide; } 6 \mathrm{M} \\
\text { Questionnaire. }\end{array}$ & $\begin{array}{l}\text { ented as mear } \\
\text { ne in one seco } \\
\text { sidual volume; } \\
\text { IWT: } 6 \text {-min W } \\
\text { : } p<0.0001 \text {; * }\end{array}$ & $\begin{array}{l} \pm S D \text {, unless oth } \\
\text { Ad; FVC: forced } \\
\text { DL,CO: diffusing ce } \\
\text { alk test; SGRQ: } \\
p<0.05 ;{ }^{* *}: p<0\end{array}$ & $\begin{array}{l}\text { erwise stated. } \\
\text { jital capacity; TL } \\
\text { apacity of the lur } \\
\text { St George's } \\
01 \text {. }\end{array}$ & $\begin{array}{l}\text { FEV1: forced } \\
\text {-C: total lung } \\
\text { ng for carbon } \\
\text { Respiratory }\end{array}$ \\
\hline
\end{tabular}

Spearman's method, unless otherwise specified. A CT responder was defined as any subject that had a decrease in the volume of the upper lobe and an increase in the nonupper lobe volume of $>10 \%$. A change in SGRQ of minus four or more points was considered a clinical responder. The association of responders with lobar volume changes and quality of life was tested using a Chi-squared test. A p-value of $<0.05$ was considered significant.

\section{RESULTS}

The clinical outcome (without CT analysis) of the initial 30 subjects in these studies has been previously reported [15]. The present group of 57 subjects with paired CT scans is an extension of the same protocols and is the first time that this data has been reported. Briefly, 346 implanted valves, a mean \pm SD of $6.06 \pm 1.96$ per subject, were placed at the initial procedure. Most (84\%) valves were placed by the catheter technique and $99.7 \%$ of the targeted upper lobe airways were successfully treated. Nearly all (54 (95\%) out of 57$)$ subjects had their bilateral upper lobes treated; three subjects received unilateral treatment because of pre-existing disease in one upper lobe, such as volume loss from a prior pneumonia. Most $(76 \%)$ of the valves were placed in segmental bronchi and the remainder in subsegmental bronchi.

\begin{tabular}{|c|c|c|c|c|}
\hline TABLE 2 & $\begin{array}{l}\text { jects wit } \\
\text { ectasis } \\
\text { n over ti }\end{array}$ & $\begin{array}{l}\text { noderat } \\
\text { erved b }\end{array}$ & $\begin{array}{l}\text { nomplet } \\
\text { nputed }\end{array}$ & $\begin{array}{l}\text { bar } \\
\text { lography }\end{array}$ \\
\hline Case number & Baseline & 1 month & 3 months & 6 months \\
\hline 1 & 0 & L-3 & ND & ND \\
\hline 2 & 0 & R-3 & ND & ND \\
\hline 3 & 0 & R-4 & ND & ND \\
\hline 4 & 0 & L-2 & ND & L-3 \\
\hline 5 & 0 & R-3 & $R-3, L-3$ & ND \\
\hline 6 & $\mathrm{R}-2$ & $\mathrm{R}-2, \mathrm{~L}-3$ & ND & ND \\
\hline 7 & 0 & $\mathrm{R}-2, \mathrm{~L}-3$ & $R-2, L-3$ & ND \\
\hline 8 & 0 & ND & $R-3, L-2$ & ND \\
\hline 9 & 0 & R-4 & ND & $R-4$ \\
\hline 10 & 0 & ND & R-4 & ND \\
\hline 11 & 0 & R-3 & R-2 & ND \\
\hline 12 & 0 & $\mathrm{R}-2, \mathrm{~L}-3$ & ND & R-2, L-3 \\
\hline
\end{tabular}

L: left; R: right side; 0: none; 1: linear; 2: mild; 3: moderate; 4: complete lobe ND: scan not done.

There were no deaths in the current group of 57 subjects within 90 days of the procedure. The most frequent adverse events occurring within a day of the procedure were pneumothorax in four and bronchospasm in two subjects. One pneumothorax resolved without tube thoracostomy and the bronchospasm episodes were transient. Within a 30-day period there were 10 subjects with a COPD exacerbation with an additional 10 in a 90-day period. There were six subjects with episodes of bronchitis within 30 days and two more within 90 days. Other than episodes of dyspnoea, of which there were three within 30 days and two within 90 days, no respiratory complications occurred in $>2$ subjects in the designated time periods.

Pulmonary function, exercise and HRQL outcomes before and after treatment are shown in table 1 and are similar to those previously reported [15]. There was no significant improvement in FEV1, FVC or DL,CO, no significant decrease in TLC or $\mathrm{RV}$, and a trend for improvement in the 6MWT distance $(12 \mathrm{~m}$ $(3.6 \%) ; \mathrm{p}>0.10)$. The significant and clinically meaningful changes were improvement in HRQL as measured by SGRQ following the procedure $(\mathrm{p}<0.0001$ for mean and mean change at 6 months).

The qualitative CT data showed high agreement regarding selection for severe upper-lobe predominant emphysema between the central reviewers and the clinical sites. There was clinical site and reviewer agreement regarding upper-lobe predominance in 54 (93\%) out of 57 patients, while the remaining three disagreements were between upper-lobe predominance and diffuse disease. In two out of those three cases, the clinical site and only one of the two reviewers were in agreement. All findings were grade 3 or 4 severity (except two that were grade 2) and all but two findings were centrilobular emphysema; with one each being panacinar and paraseptal.

On follow-up, moderate or complete lobar atelectasis was observed in $12(21 \%)$ out of 57 subjects at some point in the 6 months following valve implantation (table 2). There was no 


\begin{tabular}{|c|c|c|c|c|}
\hline \multirow[t]{2}{*}{ TABLE 3} & \multicolumn{4}{|c|}{$\begin{array}{l}\text { Quantitative computed tomography } \\
\text { measurements at baseline and after treatment }\end{array}$} \\
\hline & Baseline & 1 month & 3 months & 6 months \\
\hline Subjects $\mathrm{n}$ & 57 & 34 & 34 & 16 \\
\hline \multicolumn{5}{|l|}{ Total lung } \\
\hline Volume $\mathrm{mL}$ & $6840 \pm 1375$ & $6737 \pm 1383$ & $6852 \pm 1456$ & $6429 \pm 1605$ \\
\hline Difference $\mathrm{mL}$ & & $-54 \pm 495$ & $-45 \pm 347$ & $39 \pm 305$ \\
\hline$\%$ change & & $-0.6 \pm 7.8$ & $-0.9 \pm 5.4$ & $0.6 \pm 5.3$ \\
\hline \multicolumn{5}{|l|}{ Upper lobe } \\
\hline Volume $\mathrm{mL}$ & $3419 \pm 872$ & $3058 \pm 845^{\#}$ & $3165 \pm 976^{\#}$ & $3025 \pm 1212^{\star * *}$ \\
\hline Difference $\mathrm{mL}$ & & $-328 \pm 511^{\#}$ & $-319 \pm 427^{\#}$ & $-335 \pm 444^{\star \star \star}$ \\
\hline$\%$ change & & $-9.3 \pm 14.1$ & $-9.5 \pm 12.2$ & $-10.2 \pm 12.7$ \\
\hline \multicolumn{5}{|l|}{ Nonupper lobe } \\
\hline Volume mL & $3421 \pm 867$ & $3679 \pm 869^{\#}$ & $3687 \pm 982^{\#}$ & $3404 \pm 1025^{\#}$ \\
\hline Difference $\mathrm{mL}$ & & $274 \pm 419^{\#}$ & $274 \pm 334^{\#}$ & $374 \pm 387^{\#}$ \\
\hline$\%$ change & & $9.2 \pm 13.9$ & $8.4 \pm 10.2$ & $11.6 \pm 11.6$ \\
\hline \multicolumn{5}{|l|}{ Total lung } \\
\hline Mass $\mathrm{g}$ & $728 \pm 183$ & $714 \pm 165$ & $715 \pm 181$ & $680 \pm 195$ \\
\hline Difference $\mathrm{g}$ & & $2 \pm 126$ & $-15 \pm 139$ & $-62 \pm 108$ \\
\hline$\%$ change & & $1.2 \pm 15.3$ & $-0.6 \pm 16.6$ & $-7.3 \pm 13.0$ \\
\hline \multicolumn{5}{|l|}{ Upper lobe } \\
\hline Mass g & $301 \pm 90$ & $259 \pm 75^{\star *}$ & $266 \pm 111^{\star \star \star}$ & $238 \pm 99 * * *$ \\
\hline Difference $\mathrm{g}$ & & $-36 \pm 67^{\star *}$ & $-37 \pm 72^{\star \star \star}$ & $-71 \pm 63^{* \star *}$ \\
\hline$\%$ change & & $-10.5 \pm 19.3$ & $-12.3 \pm 19.5$ & $-22.6 \pm 15.9$ \\
\hline \multicolumn{5}{|l|}{ Nonupper lobe } \\
\hline Mass $\mathrm{g}$ & $427 \pm 111$ & $455 \pm 105$ & $449 \pm 86$ & $442 \pm 113$ \\
\hline Difference $\mathrm{g}$ & & $37 \pm 75^{*}$ & $22 \pm 96$ & $9 \pm 71$ \\
\hline$\%$ change & & $10.2 \pm 16.8$ & $8.0 \pm 17.5$ & $3.0 \pm 15.0$ \\
\hline \multicolumn{5}{|l|}{ Total lung } \\
\hline Density $\mathrm{g} \cdot \mathrm{mL}^{-1}$ & $0.108 \pm 0.026$ & $0.107 \pm 0.020$ & $0.105 \pm 0.019$ & $0.107 \pm 0.021$ \\
\hline $\begin{array}{l}\text { Difference } \\
\mathrm{g} \cdot \mathrm{mL}^{-1}\end{array}$ & & $0.000 \pm 0.026$ & $-0.001 \pm 0.020$ & $-0.012 \pm 0.025$ \\
\hline$\%$ change & & $2.8 \pm 19.2$ & $0.5 \pm 17.2$ & $-7.2 \pm 16.0$ \\
\hline \multicolumn{5}{|l|}{ Upper lobe } \\
\hline Density $\mathrm{g} \cdot \mathrm{mL}^{-1}$ & $0.090 \pm 0.024$ & $0.087 \pm 0.020$ & $0.084 \pm 0.022$ & $0.080 \pm 0.022$ \\
\hline $\begin{array}{l}\text { Difference } \\
\mathrm{g} \cdot \mathrm{mL}^{-1}\end{array}$ & & $-0.003 \pm 0.028$ & $3-0.003 \pm 0.019$ & $-0.016 \pm 0.028^{*}$ \\
\hline$\%$ change & & $1.2 \pm 27.3$ & $-1.9 \pm 22.5$ & $-12.1 \pm 22.4$ \\
\hline \multicolumn{5}{|l|}{ Nonupper lobe } \\
\hline Density $\mathrm{g} \cdot \mathrm{mL}^{-1}$ & $0.129 \pm 0.037$ & $0.126 \pm 0.023$ & $0.128 \pm 0.035$ & $0.136 \pm 0.040$ \\
\hline $\begin{array}{l}\text { Difference } \\
\mathrm{g} \cdot \mathrm{mL}^{-1}\end{array}$ & & $-0.002 \pm 0.027$ & $7-0.002 \pm 0.028$ & $-0.013 \pm 0.024$ \\
\hline$\%$ change & & $1.8 \pm 16.1$ & $0.0 \pm 16.2$ & $-7.3 \pm 12.8$ \\
\hline
\end{tabular}

Data are presented as mean $\pm S D$, unless otherwise stated. ${ }^{*}: p<0.0001$. *: $p<0.05 ;{ }^{* *}: p<0.01 ; * * *: p<0.001$.

atelectasis observed at any time point in $24(42 \%)$ subjects and a linear or mild degree of atelectasis was present in $21(37 \%)$ subjects. In addition, serial data showed that in six subjects with three scans, the degree of atelectasis decreased over time in one, increased in two and was stable in the other three subjects (table 2).

The quantitative CT measurements show that there was no change in the total lung volume, total lung mass or total lung density at 1,3 , or 6 months (table 3). However, there was

\begin{tabular}{|c|c|c|c|}
\hline \multirow{2}{*}{$\begin{array}{l}\text { TABLE } 4 \\
\text { Quantity } 1\end{array}$} & \multicolumn{3}{|c|}{$\begin{array}{l}\text { Changes }(\Delta) \text { in health-related quality of life, } \\
\text { quantitative computed tomography, pulmonary } \\
\text { function test and } 6 \text {-min walk test ( } 6 \mathrm{MWT} \text { ) results }\end{array}$} \\
\hline & Quantity 2 & $\begin{array}{l}\text { Spearman's } \\
\text { correlation }\end{array}$ & p-value \\
\hline$\Delta S G R Q$ & $\triangle 6 \mathrm{MWT}$ & -0.2436 & 0.1298 \\
\hline$\Delta \mathrm{SGRQ}$ & $\Delta \mathrm{FVC}$ & -0.2417 & 0.1329 \\
\hline$\Delta \mathrm{SGRQ}$ & $\Delta$ Upper lobe & 0.1659 & 0.305 \\
\hline$\Delta \mathrm{SGRQ}$ & $\Delta$ Nonupper lobe & -0.3809 & 0.0159 \\
\hline$\Delta S G R Q$ & $\Delta \mathrm{FEV}_{1}$ & -0.2245 & 0.1637 \\
\hline$\triangle 6 \mathrm{MWT}$ & $\Delta \mathrm{FVC}$ & 0.4783 & 0.0018 \\
\hline$\triangle 6 \mathrm{MWT}$ & $\Delta$ Upper lobe & -0.3316 & 0.0366 \\
\hline$\triangle 6 \mathrm{MWT}$ & $\Delta$ Nonupper lobe & 0.2991 & 0.0608 \\
\hline$\triangle 6 \mathrm{MWT}$ & $\Delta \mathrm{FEV} 1$ & 0.2734 & 0.0878 \\
\hline$\Delta \mathrm{FVC}$ & $\Delta$ Upper lobe & -0.3105 & 0.0512 \\
\hline$\Delta \mathrm{FVC}$ & $\Delta$ Nonupper lobe & 0.3049 & 0.0557 \\
\hline$\Delta$ Upper lobe & $\Delta$ Nonupper lobe & -0.473 & 0.0023 \\
\hline$\Delta$ Upper lobe & $\Delta \mathrm{FEV} 1$ & -0.449 & 0.0037 \\
\hline$\Delta$ Nonupper lobe & $\Delta \mathrm{FEV}_{1}$ & 0.3709 & 0.0185 \\
\hline
\end{tabular}

significant decreases at all time points in the treated upper lobe volume and mass and significant increases in the untreated nonupper lobes volumes. The average change in lobar volumes was $\sim 300 \mathrm{~mL}$, or $10 \%$. The mean $\pm \mathrm{SD}$ interobserver variation (range) in lobar volume was $2 \pm 2 \%(0-5 \%)$ or $35 \pm 31 \mathrm{~mL}(4-$ $80 \mathrm{~mL}$ ).

There was a strong correlation between the functional measurement of TLC by plethysmography and the CT

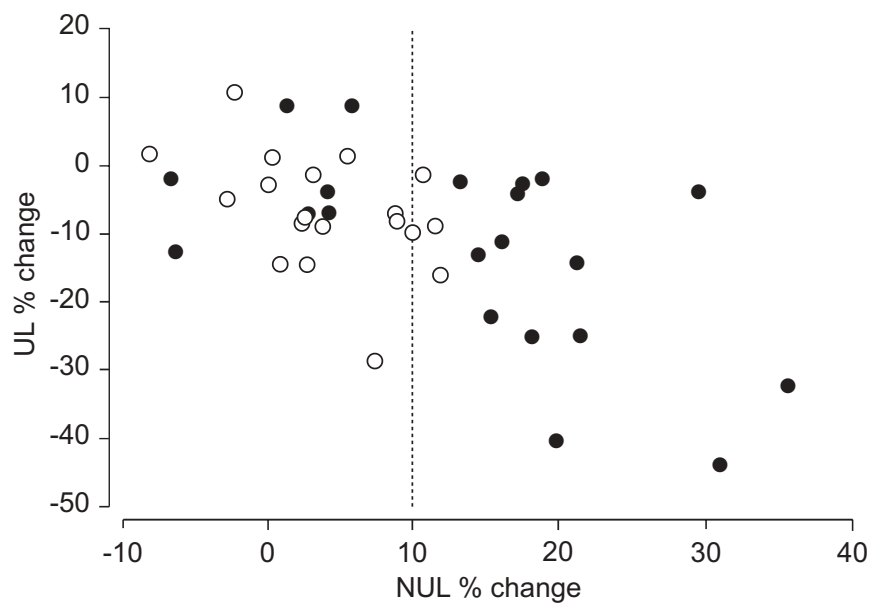

FIGURE 1. Scatter plot of percentage change in upper lobe (UL) volume change compared with nonupper lobe (NUL) volume change. •: St George's Respiratory Questionnaire (SGRQ) responders; O: SGRQ nonresponders, with a responder defined as a four-point or greater change; $\cdots .$. : threshold for a NUL response at $10 \%$. 


\begin{tabular}{|c|c|c|c|}
\hline \multirow[t]{2}{*}{ TABLE 5} & \multicolumn{3}{|c|}{$\begin{array}{l}\text { St George's Respiratory Questionnaire (SGRQ) } \\
\text { and computed tomography (CT) volume } \\
\text { comparisons using all } 40 \text { subjects with } \\
\text { 3- or 6-month paired CT data }\end{array}$} \\
\hline & & CT responder & CT nonresponder \\
\hline \multicolumn{2}{|c|}{ SGRQ responder } & $14(35)$ & 7 (18) \\
\hline \multicolumn{2}{|c|}{ SGRQ nonresponder } & $4(10)$ & $15(38)$ \\
\hline
\end{tabular}

measurement of total lung volume. There were 56 paired samples obtained from baseline studies $\left(\mathrm{r}^{2}=0.77\right)$ and 138 total samples $\left(\mathrm{r}^{2}=0.79\right)$.

Correlations between 6MWT and PFT changes, HRQL changes, and changes in upper lobe and nonupper lobe volumes are shown in table 4 . These indicate the correlation with improved SGRQ was a nonupper lobe volume increase. The PFT and 6MWT changes did not correlate with improved HRQL. There are correlations between some 6MWT and PFT measures and improvement in FEV1 is correlated with a greater upper lobe volume decrease, but not with HRQL. Figure 1 shows the upper lobe and nonupper lobe changes which indicate that $a \geqslant 10 \%$ nonupper lobe volume could define a threshold for a CT response. Therefore, a subject with $10 \%$ increase in nonupper lobe volume and any decrease of upper lobe volume was defined as a CT responder. Using results from all 40 subjects with 3- or 6-month data (using 3month if there was no 6-month data), these CT responders were compared with subjects with a greater than four-point change in SGRQ (table 5). There was a highly significant correlation between subjects that had an interlobar volume shift and HRQL $(\mathrm{p}<0.01)$.

\section{DISCUSSION}

The present study shows that the minimally invasive procedure of $I B V_{\circledR}$ Valve (Spiration, Inc.) placement in the upper lobe bronchial segments decreases the end-inspiratory volume of the (more diseased) upper lobes and increases the volume of the untreated (less diseased) lobes, without producing an overall lung volume reduction. Furthermore, these lobar volume changes are significantly associated with clinically meaningful improvements in HRQL in subjects with severe upper-lobe predominant emphysema.

Until recently, LVRS or lung transplantation have been the only options for palliative treatment of end-stage emphysema. The NETT demonstrated that LVRS improves survival, HRQL and exercise capacity for as much as 6 yrs [3]. However, due to the significant morbidity and mortality associated with LVRS, many investigators have searched for a procedure to reduce lung volume without subjecting the patients to major surgery. Therefore, minimally invasive procedures that allow the treatment of severely diseased patients is a very active area of research [15, 22-24].

Most minimally invasive procedures started with the hypothesis that lung volume reduction via atelectasis would be the major mechanism for improvement. The present study shows that, according to CT assessment, atelectasis is infrequent, can be delayed in onset, and is often transient. This finding has also been reported in studies using other bronchial valves [25], raising the question about the original hypothesis that bronchial valves result in reduction of total lung volume [15, 23].

In the present study, quantitative CT was used to measure the changes in lobar lung volume due to bronchial valve placement. These data show that, while total lung volume, as measured by
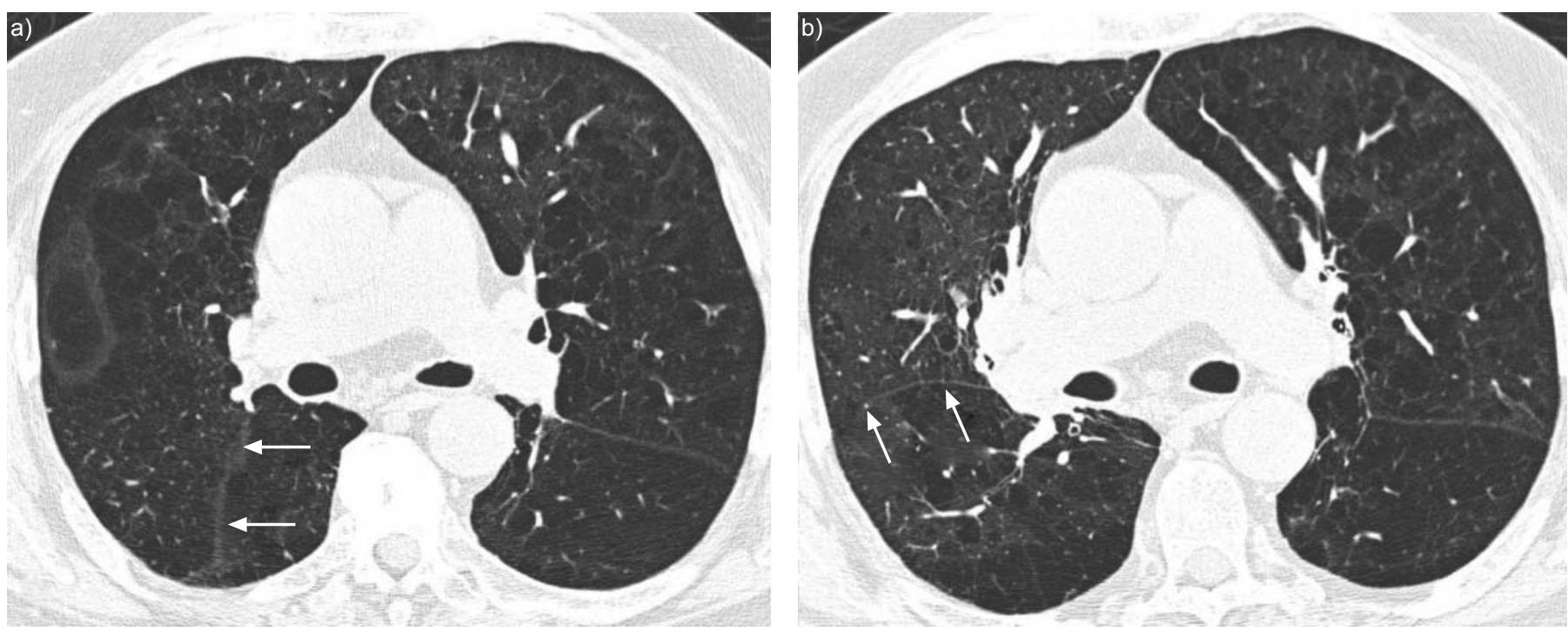

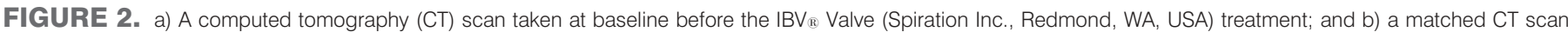

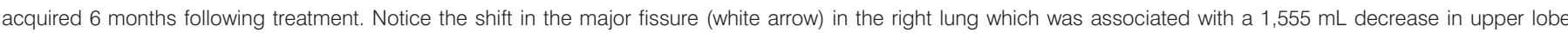
volume and a 1,200 mL increase in nonupper lobe volume. 
CT and many other parameters such as TLC and FEV1, does not change, there is a significant decrease in the volume of the upper lobes. Since there is a compensatory change in the volume of the nonupper lobes, this change cannot be assessed using global measures and this probably explains why changes in pulmonary function cannot be assessed. An example of this change in lobar volume is illustrated in figure 2, where the major fissure in the right lung is clearly shifted anteriorly following valve placement corresponding to a 1,555 $\mathrm{mL}$ decrease in upper lobe volume and a 1,200 mL increase in nonupper lobe volume. This change in the treated lobe lung volume is similar to that reported in a small group of subjects at 7 and 30 days [26]. A significant volume change was documented in the present study 6 months following valve implantation, along with a decrease in upper lobe mass, suggesting less ventilation and perfusion to the treated lobes. Furthermore, an interlobar volume shift to the nontreated lobes was reported, which was associated with an improvement in the quality of life in the valve recipients. This improved HRQL is greatest on the impact component of the SGRQ, which measures factors such as being able to do household chores, talking without dyspnoea and feeling in control of their respiratory disease. The exact physiological mechanisms for improved HRQL is not apparent from these data, but the shift of volume and mass away from the treated lobes suggests the mechanism is related to more ventilation and perfusion to the untreated and less-diseased nonupper lobes.

The present authors propose that a lack of decrease in the upper lobe volume of all subjects could be due to a higher degree of collateral ventilation. Collateral ventilation has been shown to be an important method of gas movement in many subjects [27]. Collateral ventilation is slower than bronchial ventilation, so a modest degree of collateral ventilation may prevent complete atelectasis of the treated lobe but not prevent breath-by-breath changes in the ventilation of lobes, as these quantitative $\mathrm{CT}$ data indicate.

The current study has some limitations. The CT technique was not initially standardised between institutions, which resulted in different scanning techniques being used. However, this was a lung volume study, which is different from the lung densitometry studies that are commonly reported in the emphysema literature and are very reliant on CT protocol [19, 28]. In the current study, the interlobar fissure was identifiable in all of the CT scans; therefore, the present authors are confident that this limitation was overcome and the changes in lobar volume were quantified. A second limitation of the CT protocol was that there was no standardisation of inspiration during the CT scan. However, all of these subjects had very severe emphysema and, since they were breathing at or near TLC continuously and there was no change in the physiological TLC or CT measured total lung volume, it is likely that size of breath the subjects took during the CT scans were comparable and that the measured changes in lobar volume are reliable. In addition, not all of the CT scans used continuous acquisition and, therefore, contained gaps between the sections. However, it is well established from pathological studies that this type of volume sampling provides a reliable and unbiased estimate of volume, so the present authors are confident that the measurements taken reflect the volume of the total lung and individual lobes [29, 30]. Another limitation of the current study is that the fissures were manually traced by an observer. Furthermore, some of the CT scans were obtained using thick slices and some of the fissures were probably incomplete (data not available), which will produce some variation in the measurement of lobar volume. However, the interobserver variation due to manual tracing was measured to be $\leqslant 5 \%(80 \mathrm{~mL})$, which is well within the standard deviation of the measured lobar volume and, therefore, not likely to affect the results significantly. Finally, the present study had a relatively short-term follow-up with $\mathrm{CT}$ compared with the 6 yr follow-up now reported in studies for LVRS. The IBV Valve (Spiration, Inc.) has been shown to have durable HRQL effects for 12 months [31]. These studies show that, similar to LVRS in the early stages, there is a change in some measure of lung volume and an improvement in quality of life suggesting that this technique may provide long-term benefits.

In conclusion, the current study shows that the implantation of bronchial valves results in changes in regional lung volumes that are associated with an improvement of patient quality of life. The present authors propose that the most common mechanism of action of bilateral bronchial valve treatment in severe upper-lobe predominant emphysema is not total lung volume reduction but a redirection, an inter-lobar shift, of inspired air to less diseased lung tissue.

\section{ACKNOWLEDGEMENTS}

The authors wish to acknowledge and thank the $\mathrm{IBV}_{\mathbb{B}}$ Valve Pilot Trial Research Team: R. McKenna (Principal Investigator), Z. Mohsenifar (Co-Principal Investigator) and C. Geaga (Principal Clinic Coordinator; Cedars-Medical Center, Los Angeles, CA); A. Mehta (Principal Investigator), T. Gildea (Co-Principal Investigator), Y. Meli (Principal Clinic Coordinator), M. Machuzak and S. Murthy (Cleveland Clinic Foundation (CCF), Cleveland, OH); R. Maxfield (Principal Investigator), M. Ginsburg (Co-Principal Investigator), F. Brogan (Principal Clinic Coordinator), A. Di Mango, B. Thomahow, C. Yip, J. Sonett and P. Jellen (Columbia University Medical Center, New York, NY); Momen Wahidi, MD (Principal Investigator); T. D'Amico (Co-Principal Investigator), L.S. Brown (Principal Clinic Coordinator) and J. Davies (Duke University Medical Center, Durham, NC); Praveen Mathur (Principal Investigator); F. Sheski (CoPrincipal Investigator), K. Keller (Principal Clinic Coordinator) and A. Hempfling (Indiana University Hospital, Indianapolis, IN); D. Ost (Principal Investigator), T. Arunabh (Co-Principal Investigator), R. Ramdeo (Principal Clinic Coordinator) and S. Lilavois (North Shore - Long Island Jewish Health System, Manhasset, NY); P. Diaz (Principal Investigator), P. Ross (Co-Principal Investigator), M. Rittinger (Principal Clinic Coordinator), A. El-Sayed Abbas, B. Massey, J. Drake, M. Lucarelli, N. Bhatt, R. Compton and S. Islam (Ohio State University, Columbus, $\mathrm{OH}$ ); Robert Cerfolio, MD, (Principal Investigator); S. Pereira (Co-Principal Investigator), J. Alexander (Principal Clinic Coordinator), A. Bryant, C. Miller, K. Willie and S. Calloway (University of Alabama at Birmingham, Birmingham, AL); D. Sterman (Principal Investigator), A. Musani (Co-Principal Investigator), B. Finkel (Principal Clinic Coordinator), A. Haas, C. Gillespie, D. Lipson, M. Machuzak, M. Sims and S. Leh (University of Pennsylvania Medical Center, Philadelphia, PA); J. Truwit (Principal Investigator), Y.M. Shim (Co-Principal Investigator), P. Donowitz (Principal Clinic Coordinator), A. Vinayak, 
H. Hanna, M. Patel and R. Campbell (University of Virginia Health System, Charlottesville, VA); D. Wood (Principal Investigator), M. Mulligan (Co-Principal Investigator), J.A. Broeckel Elrod (Principal Clinic Coordinator) and L. Harrison (University of Washington Medical Center, Seattle, WA; all USA).

The authors also wish to acknowledge A-T. Tran (Vancouver General Hospital, Vancouver, BC, Canada) for the development and support of the CT analysis software and database and A. Mugglin (University of Minnesota, Minneapolis, MN, USA) for statistical analysis and advice.

\section{REFERENCES}

1 Mannino DM, Buist AS. Global burden of COPD: risk factors, prevalence, and future trends. Lancet 2007; 370: 765-773.

2 Murray CJ, Lopez AD. Global mortality, disability, and the contribution of risk factors: Global Burden of Disease Study. Lancet 1997; 349: 1436-1442.

3 Naunheim KS, Wood DE, Mohsenifar Z, et al. Long-term follow-up of patients receiving lung-volume-reduction surgery versus medical therapy for severe emphysema by the National Emphysema Treatment Trial Research Group. Ann Thorac Surg 2006; 82: 431-443.

4 Brenner M, McKenna RJ Jr, Gelb AF, Fischel RJ, Wilson AF. Rate of FEV1 change following lung volume reduction surgery. Chest 1998; 113: 652-659.

5 Cassina PC, Teschler H, Konietzko N, Theegarten D, Stamatis G. Two-year results after lung volume reduction surgery in $\alpha_{1}$-antitrypsin deficiency versus smoker's emphysema. Eur Respir J 1998; 12: 1028-1032.

6 Ferguson GT, Fernandez E, Zamora MR, Pomerantz M, Buchholz J, Make BJ. Improved exercise performance following lung volume reduction surgery for emphysema. Am J Respir Crit Care Med 1998; 157: 1195-1203.

7 Gelb AF, McKenna RJ Jr, Brenner M, Epstein JD, Zamel N. Lung function $5 \mathrm{yr}$ after lung volume reduction surgery for emphysema. Am J Respir Crit Care Med 2001; 163: 1562-1566.

8 Hamacher J, Bloch KE, Stammberger U, et al. Two years' outcome of lung volume reduction surgery in different morphologic emphysema types. Ann Thorac Surg 1999; 68: 1792-1798.

9 Naunheim KS, Wood DE, Krasna MJ, et al. Predictors of operative mortality and cardiopulmonary morbidity in the National Emphysema Treatment Trial. J Thorac Cardiovasc Surg 2006; 131: 43-53.

10 Ingenito EP, Berger RL, Henderson AC, Reilly JJ, Tsai L, Hoffman A. Bronchoscopic lung volume reduction using tissue engineering principles. Am J Respir Crit Care Med 2003; 167: 771-778.

11 Ingenito EP, Reilly JJ, Mentzer SJ, et al. Bronchoscopic volume reduction: a safe and effective alternative to surgical therapy for emphysema. Am J Respir Crit Care Med 2001; 164: 295-301.

12 Toma TP, Hopkinson NS, Hillier J, et al. Bronchoscopic volume reduction with valve implants in patients with severe emphysema. Lancet 2003; 361: 931-933.
13 Toma TP, Hopkinson NS, Polkey MI, Geddes DM. Endobronchial volume reduction: a myth or a marvel? Semin Respir Crit Care Med 2004; 25: 399-404.

14 Venuta F, de Giacomo T, Rendina EA, et al. Bronchoscopic lung-volume reduction with one-way valves in patients with heterogenous emphysema. Ann Thorac Surg 2005; 79: 411-416.

15 Wood DE, McKenna RJ Jr, Yusen RD, et al. A multicenter trial of an intrabronchial valve for treatment of severe emphysema. J Thorac Cardiovasc Surg 2007; 133: 65-73.

16 Hopkinson NS, Toma TP, Hansell DM, et al. Effect of bronchoscopic lung volume reduction on dynamic hyperinflation and exercise in emphysema. Am J Respir Crit Care Med 2005; 171: 453-460.

17 The National Emphysema Treatment Trial Research Group, Rationale and design of The National Emphysema Treatment Trial: a prospective randomized trial of lung volume reduction surgery. Chest 1999; 116: 1750-1761.

18 Coxson HO, Chan IH, Mayo JR, Hlynsky J, Nakano Y, Birmingham CL. Early emphysema in patients with anorexia nervosa. Am J Respir Crit Care Med 2004; 170: 748-752.

19 Yuan R, Mayo JR, Hogg JC, et al. The effects of radiation dose and CT manufacturer on measurements of lung densitometry. Chest 2007; 132: 617-623.

20 Coxson HO, Mayo JR, Behzad H, et al. Measurement of lung expansion with computed tomography and comparison with quantitative histology. J Appl Physiol 1995; 79: 1525-1530.

21 Coxson $\mathrm{HO}$, Rogers RM, Whittall KP, et al. A quantification of the lung surface area in emphysema using computed tomography. Am J Respir Crit Care Med 1999; 159: 851-856.

22 Cardoso PF, Snell GI, Hopkins P, et al. Clinical application of airway bypass with paclitaxel-eluting stents: early results. J Thorac Cardiovasc Surg 2007; 134: 974-981.

23 de Oliveira HG, Macedo-Neto AV, John AB, et al. Transbronchoscopic pulmonary emphysema treatment: 1month to 24-month endoscopic follow-up. Chest 2006; 130: 190-199.

24 Reilly J, Washko G, Pinto-Plata V, et al. Biological lung volume reduction: a new bronchoscopic therapy for advanced emphysema. Chest 2007; 131: 1108-1113.

25 Yim AP, Hwong TM, Lee TW, et al. Early results of endoscopic lung volume reduction for emphysema. J Thorac Cardiovasc Surg 2004; 127: 1564-1573.

26 Fraioli F, Calabrese FA, Venuta F, et al. MDCT assessment of lung volume in patients undergoing bronchial stenting for treatment of pulmonary emphysema: correlation with respiratory tests and personal experience. Radiol Med (Torino) 2006; 111: 749-758.

27 Hogg JC, Macklem PT, Thurlbeck WM. The resistance of collateral channels in excised human lungs. J Clin Invest 1969; 48: 421-431.

28 Newell JD Jr, Hogg JC, Snider GL. Report of a workshop: quantitative computed tomography scanning in longitudinal studies of emphysema. Eur Respir J 2004; 23: 769-775.

29 Gundersen HJG, Bendtsen TF, Korbo L, et al. Some new, simple and efficient stereological methods and their use in pathological research and diagnosis. APMIS 1988; 96: 379-394. 
30 Michel RP, Cruz-Orive LM. Application of the Cavalieri principle and vertical sections method to lung: estimation of volume and pleural surface area. J Microsc 1988; 150: 117-136.
31 Sterman D, Wood D, McKenna R, et al. A multicenter trial of the intrabronchial valve for the treatment of severe emphysema: one-year results. Chest 2005; 128: Suppl., 162 S. 